\title{
Achilles tendon rupture: physiotherapy and endoscopy-assisted surgical treatment of a common sports injury
}

REVIEW

This article was published in the following Dove Press journal:

Open Access Journal of Sports Medicine

13 December 2010

Number of times this article has been viewed

\author{
Mahmut Nedim Doral ${ }^{1,2}$ \\ Murat Bozkurt ${ }^{3}$ \\ Egemen Turhan ${ }^{4}$ \\ Gürhan Dönmez ${ }^{2}$ \\ Murat Demire ${ }^{5}$ \\ Defne Kaya ${ }^{2}$ \\ Kıvanç Ateșok ${ }^{7}$ \\ Özgür Ahmet Atay' \\ Nicola Maffulli ${ }^{6}$
}

'Department of Orthopedics and Traumatology, ${ }^{2}$ Department of Sports Medicine, Hacettepe University School of Medicine, Sihhiye, Ankara, Turkey; ${ }^{3}$ Department of Orthopedics and Traumatology, Ankara Etlik Ihtisas Training and Research Hospital, Ankara, Turkey; ${ }^{4}$ Department of Orthopedics and Traumatology, Zonguldak Karaelmas University School of Medicine, Zonguldak, Turkey; ${ }^{5}$ Department of Orthopedics and Traumatology, Ankara Bayındır Medical Center, Ankara, Turkey; ${ }^{6}$ Centre for Sports and Exercise Medicine, Barts and The London School of Medicine and Dentistry, Queen Mary University of London, London, UK; ${ }^{7}$ St. Michael's Hospital Division of Orthopaedics Musculoskeletal Research Lab, Toronto, Ontario, Canada
Correspondence: Mahmut Nedim Doral Department of Orthopedics and Traumatology, Hacettepe University School of Medicine, Sıhhiye, Ankara, Turkey

Tel +90 3 |2 305 |209

Fax +90 312305 I347

Email ndoral@hacettepe.edu.tr

\begin{abstract}
Although the Achilles tendon (AT) is the strongest tendon in the human body, rupture of this tendon is one of the most common sports injuries in the athletic population. Despite numerous nonoperative and operative methods that have been described, there is no universal agreement about the optimal management strategy of acute total AT ruptures. The management of AT ruptures should aim to minimize the morbidity of the injury, optimize rapid return to full function, and prevent complications. Since endoscopy-assisted percutaneous AT repair allows direct visualization of the synovia and protects the paratenon that is important in biological healing of the AT, this technique becomes a reasonable treatment option in AT ruptures. Furthermore, Achilles tendoscopy technique may decrease the complications about the sural nerve. Also, early functional postoperative physiotherapy following surgery may improve the surgical outcomes.
\end{abstract}

Keywords: Achilles tendon rupture, percutaneous repair, endoscopic control, growth factors

\section{Introduction}

It is well known that the Achilles tendon (AT) has a high capacity to withstand tensional forces created by the movements of the human body, and so it is the strongest and thickest tendon in the human body. ${ }^{1,2}$ In spite of its size and strength, there is a high incidence of AT injuries, and it has been stated that $6 \%-18 \%$ of all sporting injuries involve the AT. AT ruptures commonly occur during sporting activities; furthermore, there is a tendency of increase in the incidence of ruptures because of 'weekend warriors' who are over 30 years of age. AT ruptures are reported as the third most frequent major tendon rupture, following rotator cuff and quadriceps ruptures. ${ }^{3,4}$ Despite numerous nonoperative (casting or functional bracing) and operative methods, optimal treatment of AT ruptures remains controversial, and management is still determined by the preferences of the surgeon and the patient.

To date, clinical studies have focused on cast immobilization, open surgical repair, and minimally invasive percutaneous repair. Cast immobilization may lead to suboptimal healing, with elongation of the tendon; however, reduced strength of the calf muscles and unacceptably high rate of rerupture with an incidence up to $39 \%$ seem major disadvantages of this modality. ${ }^{5-10}$ Open surgical repair of the AT is the commonly preferred method, but it carries specific risks, including adhesions between the tendon and the skin, infection, and particularly wound breakdown. ${ }^{11-13}$ The advantages of the operative and conservative methods are combined in minimally invasive percutaneous repair technique, and this technique has become popular in recent years. The major disadvantages of percutaneous repair technique are not being able to direct visualiza- 
tion of the tendon ends and complications about sural nerve entrapment; however, these problems may be overcome by performing the percutaneous repair under endoscopic control. ${ }^{14-16}$ Application of autologous growth factors also seems promising to improve the potential of biological tissue healing response. ${ }^{17-21}$ One of the keystones of a successful treatment is early physiotherapy after surgical approach.

\section{Endoscopy-assisted percutaneous repair}

The operation is performed with the patient in the prone position and under local infiltration anesthesia without a tourniquet. There is no need to administer antibiotic or antithrombotic prophylaxis. Before starting the procedure, the rupture site and location of the gap are marked (Figure 1). Subsequently, to minimize local bleeding, proximal (about $5 \mathrm{~cm}$ ) and distal (about $4 \mathrm{~cm}$ ) to the palpated gap, the skin, the subcutaneous tissues, and the peritendon are infiltrated with $20-50 \mathrm{~mL} 0.9 \%$ saline solution with local anesthetic $\left(1 \%\right.$ Citanest $^{\circledR} 5 \mathrm{~mL}+0.5 \%$ Marcain $\left.^{\circledR} 5 \mathrm{~mL}\right)$ around the eight planned stab wounds, four medial and four lateral to the tendon, distributed evenly proximally and distally to the ruptured area (Figure 2). No other medications, nerve blocks, or other types of anesthetics are administered.

Using the nick and spread technique, these puncture holes are later enlarged and used for needle entry. Special attention is paid to the lateral AT area, especially proximally, where the sural nerve lies close to and crosses the AT. During the injection of local anesthetic or at any time during the procedure, the patient is prompted to report any paresthesia or pain in the area of distribution of the sural nerve. If pain is reported, the injection site is shifted $0.5-1 \mathrm{~cm}$ toward the midline. The tendon and paratenon are examined with

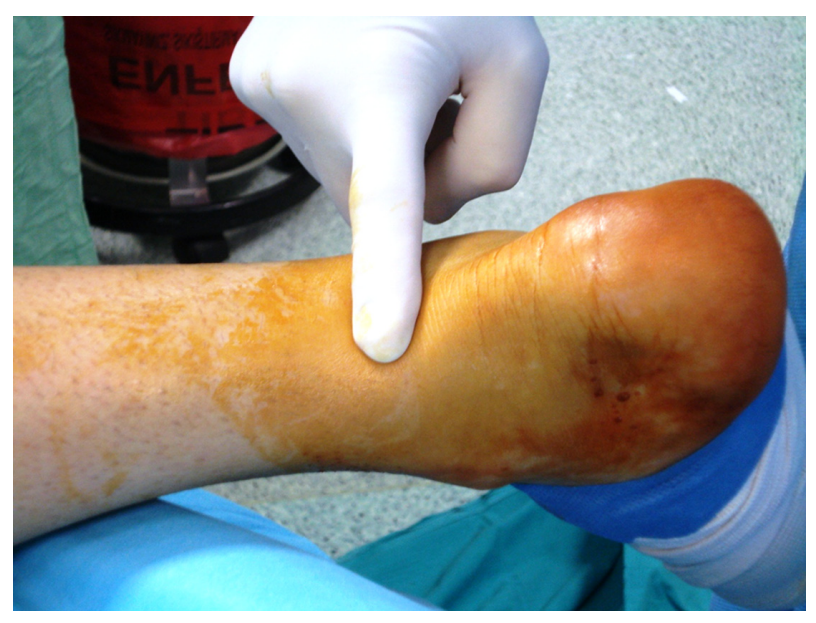

Figure I Palpation of the gap between the ruptured tendon ends.

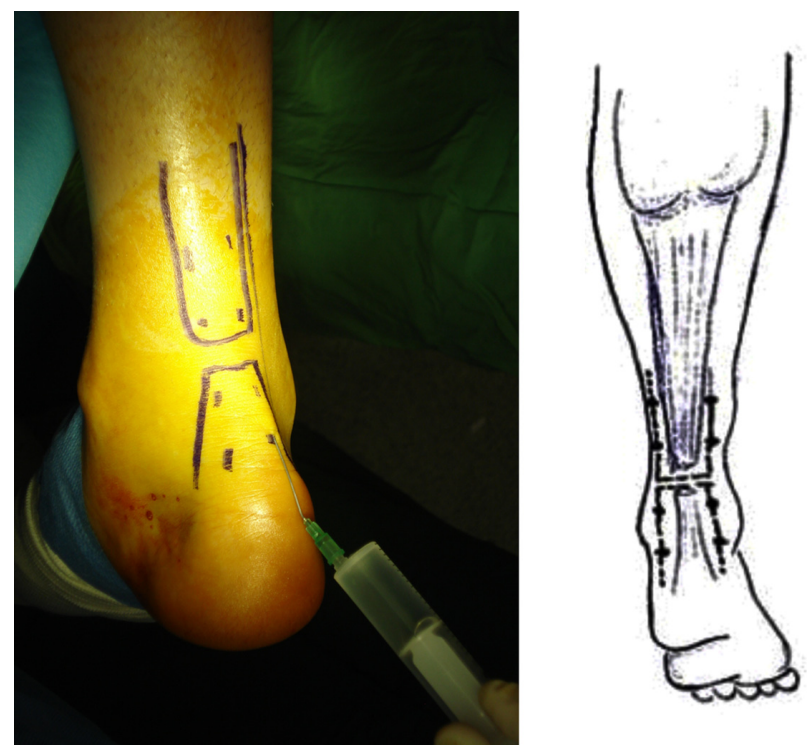

Figure 2 Local anesthetic injection to the subcutaneous tissues from the stab incisions.

a $30^{\circ}$ arthroscope (Smith and Nephew, London, UK) via the distal medial incision, and the injured foot is positioned in $\sim 15^{\circ}$ of plantar flexion (Figure 3). After the level of the rupture has been determined, the continuity of the surrounding tissues together with their consistency and vascularization are evaluated. The torn ends of the AT are inspected and, if necessary, are manipulated within the paratenon. The passing of the suture through the AT is also controlled with the scope. In this study, we used an Ethibond No. 5 or PDS No. 5 (Ethicon Inc, Johnson and Johnson, Somerville, NJ) suture with a modified Bunnell configuration. The needle with the PDS or Ethibond suture is first introduced through the upper medial portal (Figure 4A, B). To ensure that the AT is caught fully by the needle, the tendon is gently palpated between the thumb and the index finger of the opposite hand. This first bite is a transverse one, and the needle emerges from the upper lateral portal (Figure 4A). The needle is then retrieved, introduced again through it, and passed through the upper lateral portal toward portal 3. The procedure is repeated in a proximal-to-distal direction going from portal 3 to portal 4 , from portal 4 to portal 5 , from portal 5 to portal
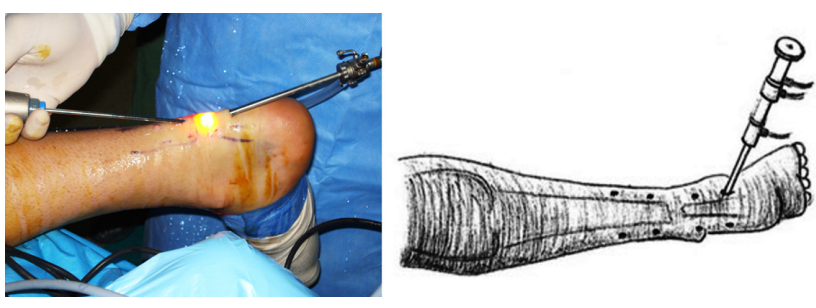

Figure 3 The placement of the arthroscope from distal medial incision. 


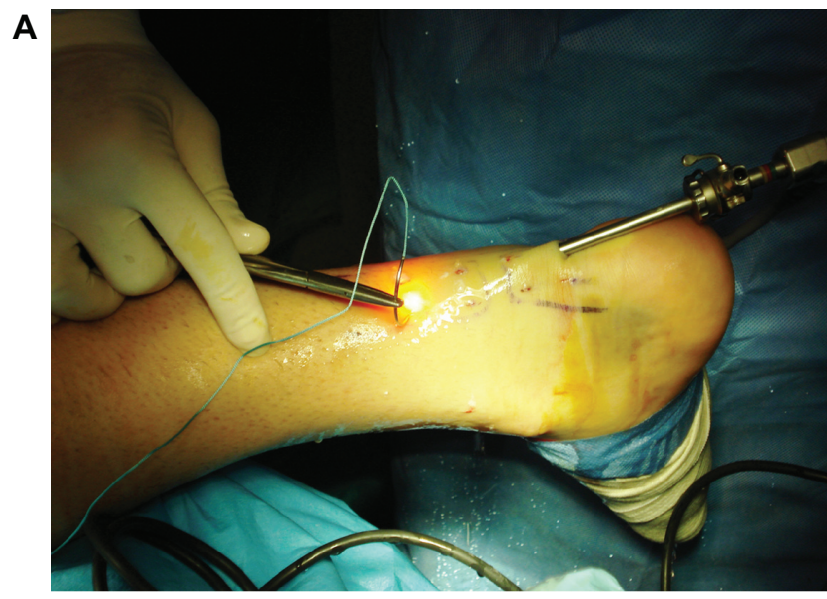

B

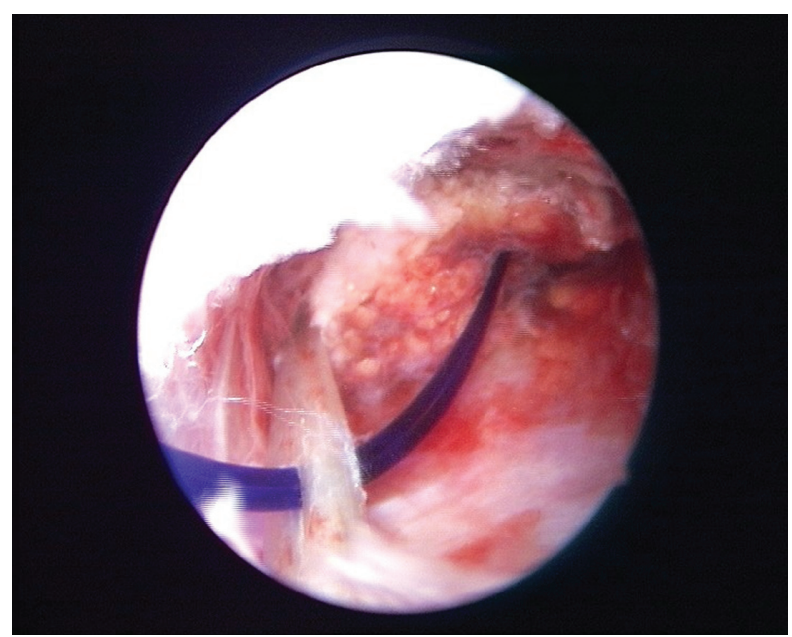

Figure 4 A modified Bunnel suture configuration was used for the procedure. A) Initially, the suture passes from the superomedial stab incision (portal I). B) The suture is carried distally with zig-zag fashion in the sequence of the number of the stab incisions under control of endoscopy.

6 , from portal 6 to portal 7 , and from portal 7 to portal 8 , the distal-most lateral portal. At this point, the needle is retrieved from portal 8, introduced through it, and passed through the distal-most lateral portal toward portal 5 , and the procedure described above is repeated backward in a distal-to-proximal direction until the needle is finally returned to the upper medial portal (Figure 5). First, we pass the suture from the proximal medial incision and out from the medial incision just above the ruptured tendon, making sure that the body of the proximal stump of the tendon is squeezed between the thumb and the index fingers (Figure 4A). Second, we pass the suture from the same incision and out from the lateral stab incision just above the tendon (Figure 4A). Finally, as in the first step, the suture is passed through this distal stab incision, carried to proximal, and then out from the superior medial side again (Figure 5). During the suture passage, the arthroscope is placed alternatively in the various entry
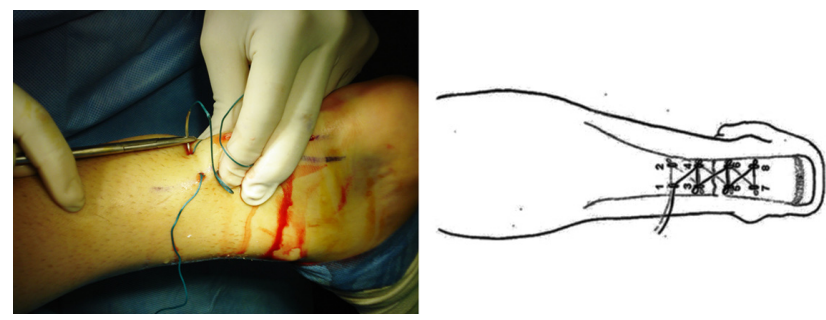

Figure $\mathbf{5}$ Final step for suturing process is carrying the suture to proximal and then out from the superomedial portal again (portal I).

portals, and the AT is inspected from the medial and lateral aspects. The proximal and distal stumps are also inspected from proximal and distal directions to make sure that the tendon stumps are juxtaposed. Through the endoscope, we also ensured that the sutures are presented in the tendon at different levels on the coronal plane so that the chance of them cutting through is minimized during the process of tensioning. Finally, the sutures are tensioned and tied in the proximal medial entry portal with the ankle in neutral position while checking the tendon approximation through the arthroscope. Before tying the sutures with the ankle in neutral position, the patient is instructed to actively dorsiand plantar-flex the ankle with the knee at $90^{\circ}$ of flexion to make sure that appropriate tension is imparted to the suture (Figure 6). A final check is performed, and the suture is fully knotted and no drainage is used. Platelet-rich plasma (PRP) is prepared by withdrawing the patients' peripheral blood and centrifuging to obtain a highly concentrated sample of platelets, which undergo degranulation to release growth factors with healing properties. Following PRP injection to the ruptured site (Figure 7), the skin stab incisions are closed with subcutaneous suture, and Steri-Strips (3M Nexcare,

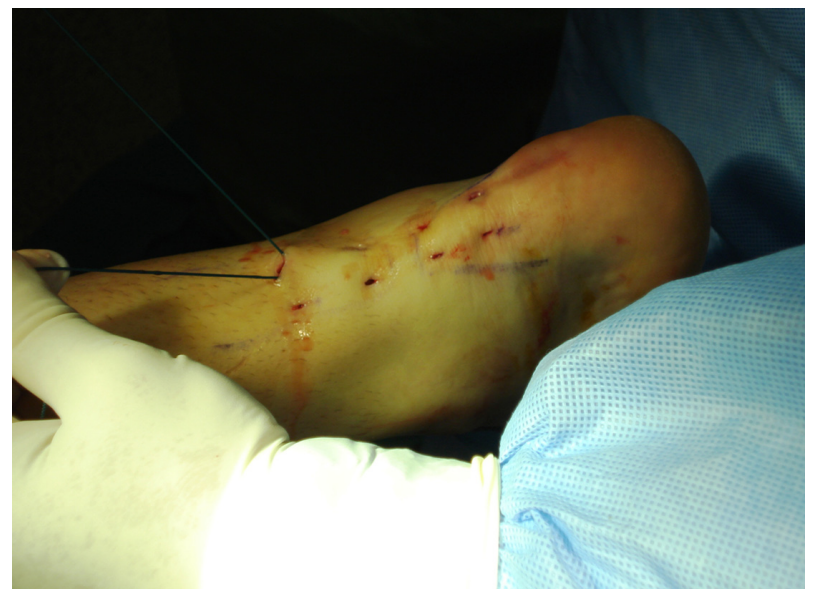

Figure 6 Before tying the suture, the patient is instructed to actively dorsi- and plantar-flex the ankle in order to make sure that appropriate tension is imparted to the suture. 


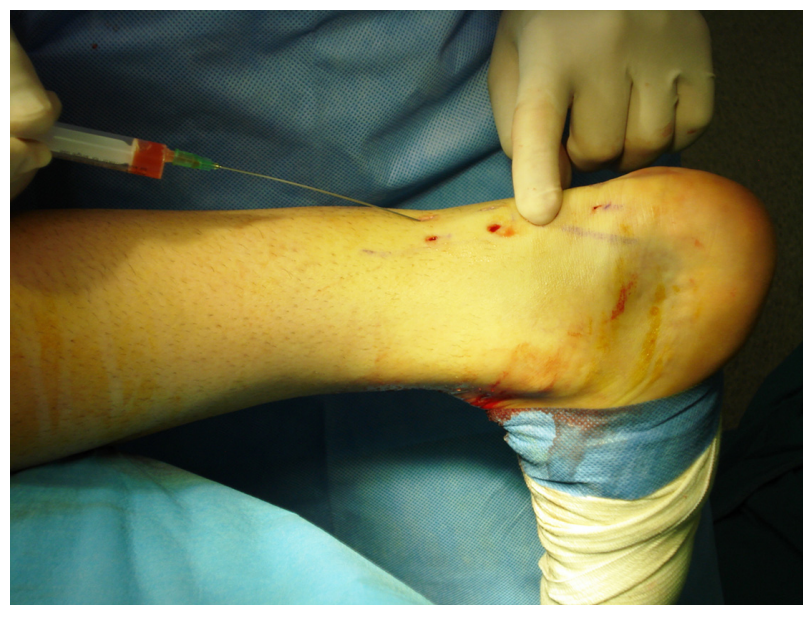

Figure 7 Injection of platelet-rich plasma.

St Paul, MN) are used for initial dressing (Figure 8). A walking brace is then applied with the ankle in the neutral position for at least 3 weeks.

\section{Physiotherapy}

A standard rehabilitation program for percutaneous repair of AT, developed based on literature in the Orthopedic Rehabilitation Clinic, Hacettepe University, is initiated immediately (Table 1). Patients are encouraged to weight-bearing ambulation with a walking brace-moon boot as tolerated (for 3 weeks only), alternating with a passive range of motion exercises. Physiotherapy, including electrical stimulation of the gastrosoleus muscle complex, cryotherapy, and therapeutic ultrasound, is applied around the AT for reduction of edema. Transverse friction massage is used to promote scar and tendon reformation. Patients are instructed to move the ankle four times a day between $20^{\circ}$ of plantar flexion and $10^{\circ}$ of dorsiflexion. The patients are requested to complete

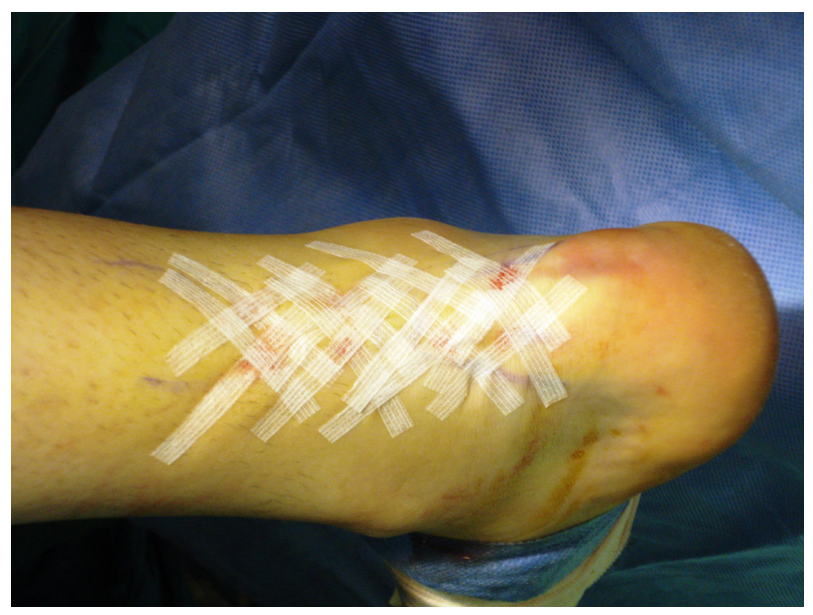

Figure 8 Final stab wound closure with sterisrtips.
Table I Rehabilitation protocol following endoscopy-assisted percutaneous Achilles tendon repair

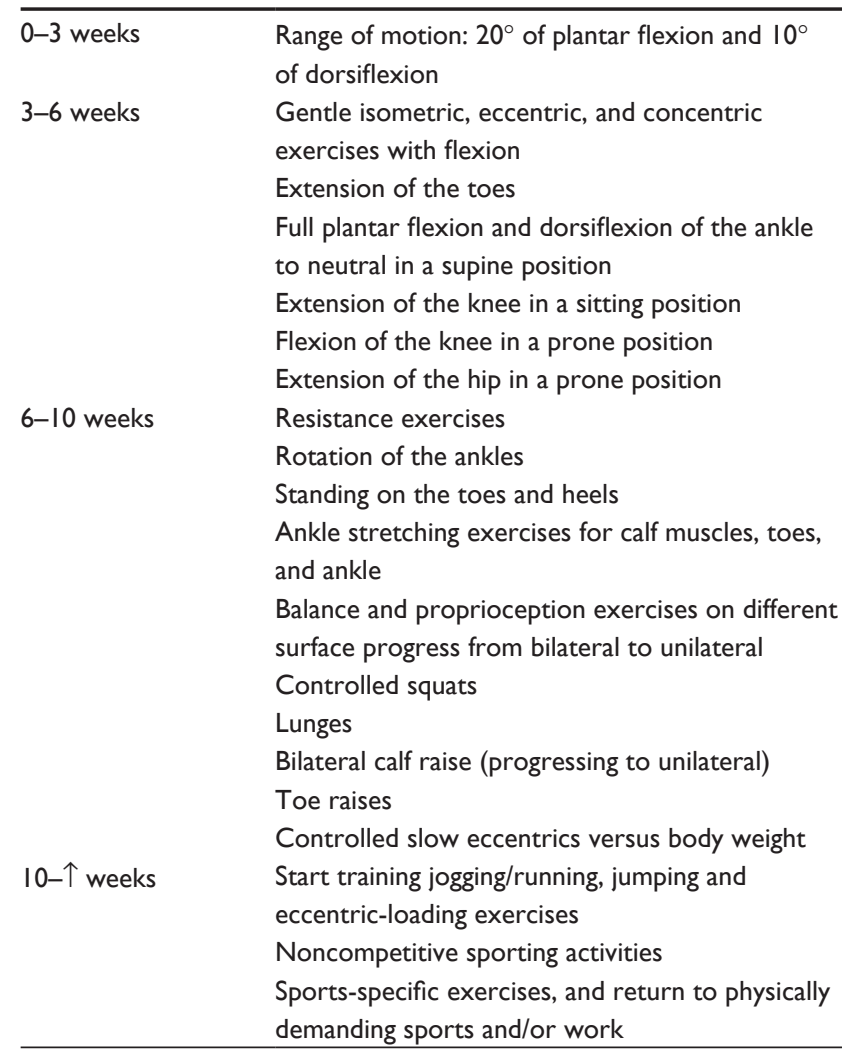

Notes: Copyright ( 2009 , Springer Verlag. Adapted with permission from Doral MN, Bozkurt M, Turhan E, et al. Percutaneous suturing of the ruptured Achilles tendon with endoscopic control. Arch Orthop Trauma Surg. 2009; 129(8):1093-I I01. ${ }^{14}$

gentle isometric, eccentric, and concentric exercises of the ankle several times a day, with flexion and extension of the toes in a supine position and full plantar flexion and dorsiflexion of the ankle to neutral in a supine position, extension of the knee in a sitting position, flexion of the knee in a prone position, and extension of the hip in a prone position within the first 3 weeks. Full weight bearing is allowed after 3 weeks postoperatively without brace. From the 6th to 10 th week, rehabilitation progresses to using elastic resistance bands; rotation of the ankles; standing on the toes and heels; ankle-stretching exercises to flexion with the help of a rubber band; stretching of the calf muscle by standing with the leg to be stretched straight behind and the other leg bent in front and leaning the body forward, with support from a wall or physiotherapist; stretching exercises for the toes and ankle against manual resistance in a sitting position; balance and proprioception exercises on different surface progress from bilateral to unilateral; and controlled squats, lunges, bilateral calf raise (progressing to unilateral), toe raises, controlled slow eccentrics versus body weight. After 10 weeks, patients are allowed training jogging/running, 
jumping and eccentric loading exercises, noncompetitive sporting activities, sports-specific exercises, and returning to physically demanding sports and/or work.

\section{Discussion}

Although ruptures of the AT are a relatively common injury encountered by the orthopedic surgeon, the incidence in the general population is difficult to determine but it is well known that most ruptures (44\%-83\%) of the AT occur during sports activities. ${ }^{2,22,23}$ Therefore, rupture of the AT is more common in males, with a male-to-female ratio ranging from $1.7: 1$ to $12: 1$, possibly reflecting the greater prevalence of males than females who are involved in sports. Typically, acute ruptures of the AT occur in men in the third or fourth decade of life, particularly those who work in a white-collar profession and play a sport occasionally. ${ }^{2,24}$

Despite many studies and meta-analyses due to increasing incidence of the AT rupture, there is no consensus about the optimal management strategy of acute total AT rupture. , $^{85-27}$ Many techniques and procedures described for the treatment of ruptured AT can be grouped under three headings: open operative, percutaneous operative, and nonoperative.

The first description of the treatment of acute AT rupture is attributed to Ambroise Paré in 1575, and he recommended that a ruptured AT be strapped with bandages dipped in wine and spices, but the results were dubious. ${ }^{2}$ Operative repair of a ruptured AT was advocated first in 1888 by Gustave Polaillon. ${ }^{2}$ But before the 20th century, AT ruptures were treated nonoperatively. ${ }^{28}$ However, in the early 20 th century, following the level IV study by Abrahamsen ${ }^{29}$ as well as Quenu and Stoinovitch, ${ }^{30}$ surgical repair of acute Achilles ruptures became more common.

There are several publications that support conservative treatment, but operative treatment modalities have been the method of choice in the last 3 decades especially for athletes and young people. The most commonly used form of nonoperative treatment is immobilization in a plaster cast, usually for a period of 6-8 weeks. These authors suggested that operative repair of a ruptured AT should be avoided, as stripping of the paratenon during an operation reduces the amount of reactive tissue that is produced later at the site of the injury, and the paratenon provides a valuable blood supply to the damaged tendon. However, conservative treatment has less functional results with higher rerupture rates and hence should be kept for elderly and low-demanding patients. ${ }^{31}$ In a systematic review, the probability of rerupture from nonoperative management was reported as $12.1 \%{ }^{32}$ A primary goal of the treatment of a rupture of the AT is to avoid lengthening of the tendon, and this cannot be achieved with nonoperative treatment.

Afterward, reduced complication rates and improved functional outcomes led many surgeons to again advocate surgical repair of acute Achilles ruptures. Numerous open surgical procedures have been proposed for repairing ruptures of the AT, ranging from simple end-to-end suturing, with Bunnell or Kessler-type sutures, to more complex repairs with use of fascial reinforcement or tendon grafts. In addition to these artificial tendon implants, materials such as absorbable polymer-carbon fiber composites, Marlex mesh (monofilament knitted polypropylene), and collagen tendon prostheses have also been used. ${ }^{2}$ Even though operative regimens present a lower rerupture rate, early functional rehabilitation, and stronger push off with a lower calf atrophy, ${ }^{8,10,25,28,32,33}$ open surgical repair also includes potential problems like joint stiffness, calf muscles atrophy, tendocutaneous adhesions, deep venous thrombosis due to prolonged immobilization, infection, scarification, algodysthrophie, and particularly the breakdown of the wound. . $^{11,32,34-37}$

Percutaneous repair technique was first described by $\mathrm{Ma}$ and Griffith ${ }^{33}$ to avoid all these complications, and this technique has become a popular technique for orthopedic surgeons. However, the technique involves difficulties in achieving satisfactory contact of the tendon stumps and adequate initial fixation. Percutaneous suturing is criticized because it provides $\sim 50 \%$ of the initial strength afforded by open repair and has a higher rate of rerupture $(6.4 \%)$ than open operative repair. ${ }^{38,39}$ Webb and Bannister ${ }^{38}$ define percutaneous repair technique as a three-midline stab incision over the posterior aspect of the tendon in order to avoid sural nerve injury, and Wagnon and $\mathrm{Akayi}^{40}$ report that this method is an effective option with functional and radiological outcomes, sural nerve entrapment seems to be a potential complication of this technique. ${ }^{8,33}$ Cadaveric dissections with computerassisted modeling in the sagittal and transverse planes showed that the sural nerve crossed the AT at, on average, $11 \mathrm{~cm}$ proximal to the calcaneal tubercle and, on average, $3.5 \mathrm{~cm}$ distal to the musculotendinous junction. ${ }^{41}$ Therefore, in this area, the nerve is especially vulnerable to iatrogenic injury during surgery, particularly minimally invasive surgery. ${ }^{41,42}$ Since minimally invasive percutaneous repair techniques do not provide direct observation, percutaneous repair of AT rupture under endoscopic control has been suggested to overcome this blindness. . $^{15,16,43,44}$

Major advantages of endoscopy-assisted percutaneous repair are allowing direct observation of the process of suturing the AT and eliminating some of the disadvantages 
of the percutaneous repair techniques, especially the evaluation of the juxtaposition of the torn ends. ${ }^{15,38,45-47}$ Since this technique allows early active ankle mobilization and weight bearing after a short period of cast immobilization, complications due to the prolonged immobilization may be prevented. Another important issue in this technique is that it could help to prevent the risk of damage to the sural nerve by allowing its direct visualization. However, knowledge of the local anatomy is crucial to place the stab wounds in the areas less likely to damage the sural nerve (Figure 9). ${ }^{1}$ Since the paratenon is protected in endoscopic repair, biological advantage to the mechanical strength of the repair furnished by the suture material could be provided. Preservation of paratenon also decreases the gliding resistance of the extrasynovial tendons after repetitive motion, as in the example of synovial covering in the healing process of the posterior cruciate ligament, where a mechanically strong AT is achieved. ${ }^{48}$ Furthermore, Achilles tendoscopy technique allows direct observation of the stab wounds and controlled juxtaposition of the tendon ends without damaging the paratenon. ${ }^{49}$ Doral et $\mathrm{al}^{27}$ highlighted the importance of endoscopic repair in protecting paratenon on biological healing of the AT

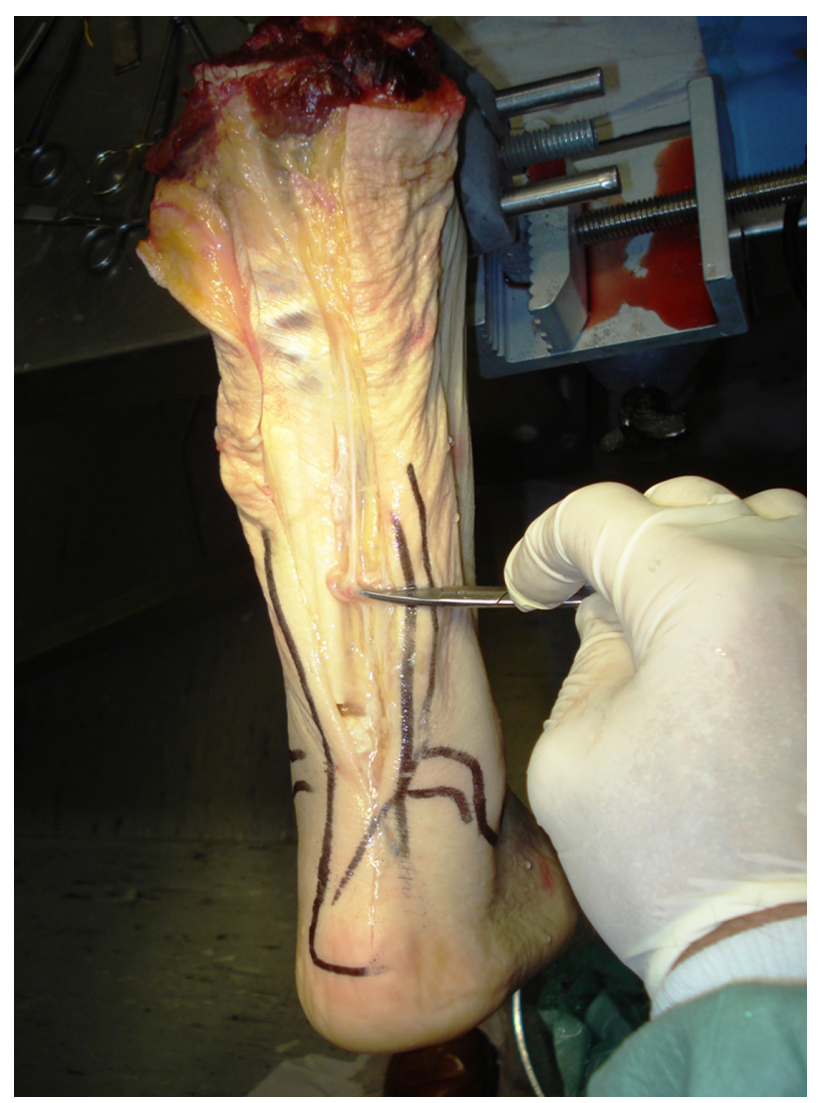

Figure 9 Cadaveric dissection of the Achilles tendon (AT). Sural nerve lies at the lateral border of the AT. ruptures. Since the paratenon is weak, our sutures may be more effective than biological healing in ruptures associated with Achilles tendinosis. ${ }^{14}$

Cretnik et $\mathrm{al}^{35}$ and Lim et $\mathrm{al}^{37}$ compared the results of percutaneous versus open AT repair in prospective randomized studies and emphasized that the percutaneous technique brings comparable functional results, with significantly lower complication rates and improved cosmetic appearance.

Buchgraber and Pässler ${ }^{50}$ compared the results of immobilization and functional postoperative treatment after using a standardized microinvasive technique for AT rupture. Their results revealed that patients undergoing functional postoperative rehabilitation with early weight bearing were hospitalized for shorter periods and lost fewer days from work than those in the cast group and had less severe calf muscle work by the injured leg than postoperative immobilization. The rerupture rate was reported no higher than after cast immobilization, but lower than after open surgical repair or conservative functional treatment alone. ${ }^{50}$ Similarly, Majewski et $\mathrm{al}^{51}$ compared postoperative below-knee cast immobilization and early functional therapy using a special shoe following percutaneous repair of acute AT ruptures. Results indicated that early mobilization in a special shoe provides a good clinical outcome and shortens the time for return to work and sports, so it is preferable to postoperative immobilization after percutaneous AT repair.

Carmont and Maffulli $^{47}$ recommended a mini open technique, with a $1.2-1.5 \mathrm{~cm}$ transverse incision at the level of the rupture, to directly observe whether the appropriate juxtaposition of the ruptured tendon ends has been achieved. This method of percutaneous repair permits a less invasive approach to the tendon and accurate opposition of the tendon ends and minimizes the chance of sural nerve injury. Although the main disadvantage of this procedure is requirement of experience on soft tissue endoscopy, we recommend practicing this technique on cadavers or amputated limbs before clinical application. ${ }^{52}$

New techniques utilizing growth factors may offer the biological potential to enhance the quality and biomechanical integrity of healing knee ligaments. ${ }^{17,18}$ In vitro studies suggested that growth factors (PRP injections) released by platelets recruit reparative cells and may augment soft tissue repair. ${ }^{19,21}$ Sánchez et al ${ }^{17}$ reported the operative management of tendons combined with the application of autologous growth factors also seems promising to improve tissue healing response and functional recovery. To accelerate the healing response and revascularization of ruptured tendon, PRP, prepared by withdrawal of patients' peripheral blood 


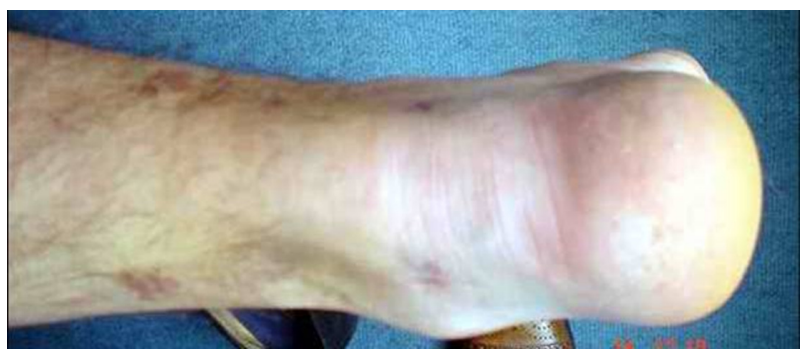

Figure 10 The appearance of the wound is cosmetic with percutaneous method.

and centrifugation to obtain a highly concentrated sample of platelets, was injected to the ruptured site of the AT. Although randomized controlled trials are necessary to claim the effects of growth factors, the use of autologous PRP is shown to be safe, reproducible, and effective in mimicking the natural processes of soft tissue and bone healing.

\section{Conclusion}

Percutaneous repair of the AT under endoscopic control with local infiltration anesthesia is a safe method when compared with open surgery or minimally invasive approaches. It is likely more cost-effective than open techniques, and, in some settings, endoscopic control carries no additional costs. Also, this technique results in excellent wound appearance without any severe complication (Figure 10). Furthermore, this procedure protects the paratenon and thus blood supplies of the tendon and should enhance biologic recovery. Direct visualization and manipulation of the tendon ends also provide stable repair that allows early weight bearing and ambulation and can be used in athletic individuals.

\section{Disclosure}

The authors report no conflicts of interest in this work.

\section{References}

1. Doral MN, Alam M, Bozkurt M, et al. Functional anatomy of the Achilles tendon. Knee Surg Sports Traumatol Arthrosc. 2010;18(5):638-643.

2. Maffulli N. Rupture of the Achilles tendon. J Bone Joint Surg (Am). 1999;81(7):1019-1036.

3. Hattrup SJ, Johnson KA. A review of ruptures of the Achilles tendon. Foot Ankle. 1985;6(1):34-38.

4. Lipscomb PR, Weiner AD. Rupture of muscles and tendons. Minn Med. 1956;39(11):731-736.

5. Jacobs D, Martens M, van Audekercke R, Mulier JC, Mulier F. Comparison of conservative and operative treatment of Achilles tendon rupture. Am J Sports Med. 1978;6(3):107-111.

6. Edna TH. Non-operative treatment of Achilles tendon ruptures. Acta Orthop Scand. 1980;51(6):991-993.

7. Fierro N, Sallis RE. Achilles tendon rupture. Is casting enough? Postgrad Med. 1995;98(3):145-152.

8. Möller M, Movin T, Granhed H, Lind K, Faxén E, Karlsson J. Acute rupture of tendo Achillis. A prospective randomized study of comparison between surgical and non-surgical treatment. J Bone Joint Surg Br. 2001;83(6):843-848.
9. Wills CA, Washburn S, Caiozzo V, Prietto CA. Achilles tendon rupture. A review of the literature comparing surgical versus nonsurgical treatment. Clin Orthop Relat Res. 1986;207:156-163.

10. Wong J, Barrass V, Maffulli N. Quantitative review of operative and nonoperative management of Achilles tendon ruptures. $\mathrm{Am} \mathrm{J}$ Sports Med. 2002;30(4):565-575.

11. Bhandari M, Guyatt GH, Siddique F, et al. Treatment of acute Achilles tendon ruptures: a systematic overview and metaanalysis. Clin Orthop Relat Res. 2002;400:190-200.

12. Bradley JP, Tibone JE. Percutaneous and open surgical repairs of Achilles tendon ruptures. A comparative study. Am J Sports Med. 1990; 18(2):188-195.

13. Ebinesan AD, Sarai BS, Walley GD, Maffulli N. Conservative, open or percutaneos repair for acute rupture of the Achilles tendon. Disabil Rehabil. 2008;30(20-22):1721-1725.

14. Doral MN, Bozkurt M, Turhan E, et al. Percutaneous suturing of the ruptured Achilles tendon with endoscopic control. Arch Orthop Trauma Surg. 2009;129(8):1093-1101.

15. Tang KL, Thermann H, Dai G, Chen GX, Guo L, Yang L. Arthroscopically assisted percutaneous repair of fresh closed Achilles tendon rupture by Kesslers suture. Am J Sports Med. 2007;35(4):589-596.

16. Thermann H, Tibesku CO, Mastrokalos DS, Pässler HH. Endoscopically assisted percutaneous Achilles tendon suture. Foot Ankle Int. 2001;22(2):158-160.

17. Sánchez M, Anitua E, Azofra J, Andía I, Padilla S, Mujika I. Comparison of surgically repaired Achilles tendon tears using platelet-rich fibrin matrices. Am J Sports Med. 2007;35(2):245-251.

18. Lopez-Vidriero E, Goulding KA, Simon DA, Sanchez M, Johnson DH The use of platelet-rich plasma in arthroscopy and sports medicine: optimizing the healing environment. Arthroscopy. 2010;26(2):269-278.

19. de Mos M, van der Windt AE, Jahr H, et al. Can platelet-rich plasma enhance tendon repair? A cell culture study. Am J Sports Med. 2008;36(6):1171-1178.

20. Kashiwagi K, Mochizuki Y, Yasunaga Y, Ishida O, Deie M, Ochi M. Effects of transforming growth factor-beta 1 on the early stages of healing of the Achilles tendon in a rat model. Scand J Plast Reconstr Surg Hand Surg. 2004;38(4):193-197.

21. Aspenberg P, Virchenko O. Platelet concentrate injection improves Achilles tendon repair in rats. Acta Orthop Scand. 2004;75(1): 93-99.

22. Suchak A, Bostick G, Reid D, Blitz S, Jomha N. The incidence of Achilles tendon ruptures in Edmonton, Canada. Foot Ankle Int. 2005;26(11):932-936.

23. Cetti R, Christensen SE, Ejsted R, Jensen NM, Jorgensen U. Operative versus nonoperative treatment of Achilles tendon rupture. A prospective randomized study and review of the literature. Am J Sports Med. 1993;21(6):791-799.

24. Sargon MF, Ozlu K, Oken F. Age-related changes in human tendo calcaneus collagen fibrils. Saudi Med J. 2005;26(3):425-428.

25. Khan RJ, Fick D, Keogh A, Crawford J, Brammar T, Parker M. Treatment of acute Achilles tendon ruptures. A metaanalysis of randomized, controlled trials. J Bone Joint Surg Am. 2005;87(10): 2202-2210.

26. Majewski M, Rickert M, Steinbrück K. Achilles tendon rupture. A prospective study assessing various treatment possibilities. Orthopade. 2000;29(7):670-676.

27. Doral MN, Tetik O, Atay OA, Leblebicioğlu G, Oznur A. Achilles tendon diseases and its management. Acta Orthop Traumatol Turc. 2002;36 Suppl 1:42-46.

28. Chiodo CP, Den Hartog B. Surgical strategies: acute Achilles ruptureopen repair. Foot Ankle Int. 2008;29(1):114-118.

29. Abrahamsen K. Ruptura tendinis Achillis. Ugesskr Laeger. 1923;85: 279-285.

30. Quenu J, Stoinovitch S. Les ruptures du tendon d'Achille. Rev Chir. 1929;48:647-678.

31. Lea RB, Smith L. Non-surgical treatment of tendo Achilles rupture. J Bone Joint Surg. 1972;54(7):1398-1407. 
32. Kocher MS, Bishop J, Marshall R, Briggs KK, Hawkins RJ. Operative versus nonoperative management of acute Achilles tendon rupture: expected-value decision analysis. Am J Sports Med. 2002;30(6): 783-790.

33. Ma GWC, Griffith TG. Percutaneous repair of acute closed ruptured Achilles tendon. A new technique. Clin Orthop. 1977;128:247-255.

34. Li J, Xu Y, Wang X. Management of soft tissue defect after Achilles tendon repair. Zhongguo Xiu Fu Chong Jian Wai Ke Za Zhi. 2007;21(4): 367-370.

35. Cretnik A, Kosanovic M, Smrkolj V. Percutaneous versus open repair of the ruptured Achilles tendon: a comparative study. Am J Sports Med. 2005;33(9):1369-1379.

36. Chiodo CP, Wilson MG. Current concepts review: acute ruptures of the Achilles tendon. Foot Ankle Int. 2006;27(4):305-313.

37. Lim J, Dalal R, Waseem M. Percutaneous vs open repair of the ruptured Achilles tendon - a prospective randomized controlled study. Foot Ankle Int. 2001;22(7):559-568.

38. Webb JM, Bannister GC. Percutaneous repair of the ruptured tendo Achillis. J Bone Joint Surg (Br). 1999;81(5):877-880.

39. Hockenbury RT, Johns JC. A biomechanical in vitro comparison of open versus percutaneous repair of tendon Achilles. Foot Ankle. 1990;11(2):67-72.

40. Wagnon R, Akayi M. The Webb-Bannister percutaneous technique for acute Achilles' tendon ruptures: a functional and MRI assessment. J Foot Ankle Surg. 2005;44(6):437-444.

41. Citak M, Knobloch K, Albrecht K, Krettek C, Hufner T. Anatomy of the sural nerve in a computer-assisted model: implications for surgical minimal-invasive Achilles tendon repair. Br J Sports Med. 2007;41(7): 456-458; discussion 458.

42. Apaydin N, Bozkurt M, Loukas M, Vefali H, Tubbs RS, Esmer AF. Relationships of the sural nerve with the calcaneal tendon: an anatomical study with surgical and clinical implications. Surg Radiol Anat. 2009; May 29 [Epub ahead of print].
43. Fortis AP, Dimas A, Lamprakis AA. Repair of Achilles tendon rupture under endoscopic control. Arthroscopy. 2008;24(6):683-688.

44. Lui TH. Endoscopic-assisted Achilles tendon repair with plantaris tendon augmentation. Arthroscopy. 2007;23(5):556.e1-556.e5.

45. Halasi T, Tállay A, Berkes I. Percutaneous Achilles tendon repair with and without endoscopic control. Knee Surg Sports Traumatol Arthrosc. 2003;11(6):409-414.

46. Rebeccato A, Santini S, Salmaso G, Nogarin L. Repair of the Achilles tendon rupture: a functional comparison of three surgical techniques. J Foot Ankle Surg. 2001;40(4):188-194.

47. Carmont MR, Maffulli N. Modified percutaneous repair of ruptured Achilles tendon. Knee Surg Sports Traumatol Arthrosc. 2008;16(2): 199-203.

48. McClelland D, Maffulli N. Percutaneous repair of ruptured Achilles tendon. J R Coll Surg Edinb. 2002;47(4):613-618

49. Momose T, Amadio PC, Zobitz ME, Zhao C, An KN. Effect of paratenon and repetitive motion on the gliding resistance of tendon of extrasynovial origin. Clin Anat. 2002;15(3):199-205.

50. Buchgraber A, Pässler HH. Percutaneous repair of Achilles tendon rupture. Immobilization versus functional postoperative treatment. Clin Orthop Relat Res. 1997;341:113-122.

51. Majewski M, Schaeren S, Kohlhaas U, Ochsner PE. Postoperative rehabilitation after percutaneous Achilles tendon repair: early functional therapy versus cast immobilization. Disabil Rehabil. 2008;30(20-22):1726-1732.

52. Turgut A, Günal I, Maralcan G, Köse N, Göktürk E. Endoscopy assisted percutaneous repair of the Achilles tendon ruptures: a cadaveric and clinical study. Knee Surg Sports Traumatol Arthrosc. 2002;10(2): $130-133$
Open Access Journal of Sports Medicine

\section{Publish your work in this journal}

Open Access Journal of Sports Medicine is an international, peer-reviewed, open access journal publishing original research, reports, reviews and commentaries on all areas of sports medicine. The manuscript management system is completely online and includes a very quick and fair peer-review system.

\section{Dovepress}

Visit http://www.dovepress.com/testimonials.php to read real quotes from published authors. 